\title{
Applied Gerontology and Minority Aging: A Millennial Goal
}

John Murphy and Charles Longino (1997) propose in their editorial that applied gerontology can move comfortably between two worlds-the abstract reasoning of scientific research and the personal reasoning of gerontological practice (negotiation within life worlds). For ease of movement, neither the scientific nor the personal modality should be taken as foundational; rather, modalities should be viewed as par and complementary to each other. Applied gerontology ideally is an interplay among multiple modalities. Capturing the essence, clients' desires should be supplementary and not subservient to abstract reasoning models. In brief, the facile movement of applied gerontology between scientific research and practice depends on resolving certain philosophical issues that underlie choices in modalities.

Lisa Groger, in this issue of the journal, focuses on minority aging and asserts that applied gerontology does not move easily between scientific research and practice due to certain problems: objectification of minorities in the research process, failure to share research funds with minority respondents, and a research focus on inappropriate factors-race instead of poverty and race differences instead of race similarities. Thus, the movement of applied gerontology between scientific research and practice is constrained under certain conditions during the research process.

Although Groger takes issue with the Murphy-Longino model, the difference in the two conceptualizations seems more apparent than real. The Groger and Murphy-Longino arguments may be two sides of the same coin: MurphyLongino presenting philosophical conditions that help applied gerontology move more easily between scientific research and practice, and Groger focusing on more specific, practical issues further along in the research chain that thwart the movement of applied gerontology between science and practice. In sum, each agrees that the movement of applied gerontology between scientific research and practice is facilitated under certain conditions and hampered under others.

As valuable as Murphy-Longino's and Groger's philosophical and practical insights into the applied gerontology process are, there is an issue fundamental to both choice of modalities and analysis and interpretation of 
data. In view of some rather dramatic demographic changes, a conceptual shift in our paradigms of minority aging may be necessary if applied gerontology is to effectively inform practice and policy on the minority elderly in the 21 st century. The older population is becoming much more diverse. Minority groups are growing more rapidly than the dominant group and will continue to do so on into the future. The increasing demographic diversity portends an increasing diversity in the attitudes, behaviors, and resources of newer cohorts of elderly. Layering onto the growing number of minority groups the unique experiences of people within these groups-people of different genders, sexual orientations, social classes, and immigration histories-increases the number of subgroups for study and adds considerably to the complexity of studying diversity. Future generations of applied gerontologists and the models they use will need to recognize, address, and deal with the multiplying facets of diversity.

Scientific gerontological research has customarily studied diversity in a rather simplistic way-comparing minority groups with the majority group. Often, comparative studies implicitly used the dominant group as the norm or standard (Stoller \& Gibson, 1997). As Groger emphasizes in her editorial, concern with differences can blind gerontologists to the significance of findings of "no difference." Furthermore, this past research, in the main, did not examine differences among various minority groups. Few studies compare African Americans, Asian Americans, Native Americans, and Hispanic Americans. Not enough studies have deconstructed these terms to recognize, for example, the diverse experiences of Chicano, Cuban, or Puerto Rican elderly categorized under the term Hispanic American or Latino elder. Finally, studies exploring variation within particular groups also are underrepresented in the minority aging literature. The challenges of aging experienced by a retired Mexican American bank president will manifest themselves differently in the life of a retired migrant farm laborer from the same ethnic background. Perhaps studies focusing on such within-group variation will suggest modifications in the labels we use for categorizing minority elders. As Mark Cohen (1998) argues:

Classifying people by color is very much like classifying cars by color. Those in the same classification look alike, superficially (if you ignore the detailed differences), but the classification tells you nothing about the hidden details of construction or about how the cars or the people will perform. (p. 12)

The problem is not unique to scientific research; it also surfaces in applied gerontological work when findings on a small select group of minority elderly are extrapolated to the minority group at large. 
In short, both our past scientific and applied gerontology research have suffered from attributing the characteristics of some of a group to all of a group, resulting in stereotypes of the minority elderly. Sociologist Jacqueline Jackson's reconstruction of the older African American woman (in Stoller \& Gibson, 1997) culled from the findings of research studies over time illustrates the point.

To illustrate with only slight exaggeration, the average old black woman lives in a blighted section of an inner city or in an isolated rural area. Poor, poorly educated and in poor health, she is economically dependent on Social Security and other income transfer or in-kind programs (e.g., food stamps, subsidized housing, and Medicaid).

This average old black woman is beset by problems, not the least of which are substandard housing in high crime areas, insufficient transportation, and inadequate access to mainstream health facilities, in part because she is stymied by and unable to cope successfully with bureaucratic institutions. If she is not gainfully employed, it is only because she is unemployed, involuntarily retired, or too ill or disabled to work. Old black women like to work because they gain dignity through working.

A poor woman, she rarely uses community resources for the elderly, such as a center for senior citizens, most often because she does not know about them nor of their eligibility requirements. ...Extremely religious and often the matriarch of an extended family, [she] is surrounded by children, grandchildren, other relatives, or fictive kin, and by friends and neighbors who gleefully minister to her instrumental and emotional needs. "Granny" is also very happy when she is given the responsibility of rearing her grandchildren. (pp. 31-32)

This stereotype of the older African American woman, based on samples of African American women who were poor, poorly educated, and working in menial occupations, continues to be used today implicitly, if not explicitly, as a model for both scientific research and applied gerontology. The critical issue is that the stereotype misfits a sizable proportion of other African American women: Dr. Mae Jemison, astronaut; Dr. Jocelyn Elders, former U.S. Surgeon General; Anita Hill, professor of law; Hazel O'Leary, immediate past U.S. Secretary of Energy; and the legions of older African American women who have moved over several decades from domestic to white-collar occupations.

Groger reminds us of the multiple ways in which discrimination throughout the life course translates into an accumulation of disadvantage in old age. The concept of "multiple jeopardy" reminds us that occupying several disadvantaged positions along systems of inequality simultaneously compounds our risk of negative outcomes in old age. When researchers think about hierarchies, it is often easier to recognize these elements of discrimination (McIntosh, 1988). This emphasis on disadvantage, however, some- 
times masks the ways in which these same hierarchies create systems of privilege. Occupying a position of privilege on hierarchies based on gender or social class contributes to diversity among people who share a disadvantaged position on hierarchies based on race or ethnicity. Images of minority groups that ignore this diversity can influence the themes we look for in our research, providing a misleading sense of reality on which to base practice and policy in a widely diverse society. As one of our colleagues used to remind us, "the probability of not seeing what you're not looking for is high" (R. Malpass, personal communication).

One way to begin to rid applied gerontology of minority group stereotypes is to reconceptualize how we study diversity. The first order of business in this process is to understand that our social structure not only imposes social categories-race, gender, class and the like-but also has a blueprint for giving or denying resources of various kinds to those located on various rungs of these race, gender, and class systems of inequality. Women, for example, are more likely to be bounded in their careers by the glass ceiling, to earn less for the same job, and to bear the personal costs of family caregiving. Minorities and the lower classes have more limited access to health, wealth, education, and the pursuit of happiness. It is important to interject here that it is not just an individual's position in the race, gender, or class hierarchy that influences her life, but some combination of memberships in these systems of inequality. For example, it is more crucial in applying research to practice to recognize the individual as a Mexican American woman of the middle class than to recognize her simply as Mexican American. It is more important to recognize a White man as an individual living homeless on the streets than simply as a White man. Analogously, the African American man who is CEO of a major corporation may share race and gender with the African American man who is a day laborer, but many of their life circumstances will differ due to different positions in the class hierarchy. Thus, it is important in our new models to recognize that people can experience disadvantage on one dimension of inequality, although at the same time experiencing privilege on another. To assume that all men are privileged over all women, or that all Whites are advantaged relative to all people of color, is to ignore the important intersections among multiple hierarchies-gender is experienced differently depending on one's race and social class, and the experience of race and social class depends on one's gender. Recognizing these interactions of multiple hierarchical positions in the new applied gerontology models will reduce stereotypes and help to pinpoint true differences in the resources, coping capacities, social relations, and social realities of older persons. 
Applied gerontologists who would use the new models also have a responsibility. They will need to listen to diverse voices and look through multiple lenses to get views of social reality in groups other than their own. It is not that researchers purposely distort information or are insensitive to minority group concerns; rather, researchers approach their work from a specific location in race, gender, and class systems of inequality. Occupying these positions shapes investigators past experiences, what they know about the world, their current attitudes, the questions they ask, what they observe, and how they interpret what they observe.

Reconceptualizing the models to produce fewer stereotypes is one way to clear the path applied gerontology travels between scientific research on and practice on minority groups in the new millenium.

Rose Campbell Gibson

University of Michigan

Eleanor Palo Stoller

Case Western Reserve University

\section{REFERENCES}

Cohen, M. N. (1998). Culture of intolerance: Chauvinism, class, and racism in the United States. New Haven, CT: Yale University Press.

McIntosh, P. (1988). White privilege and male privilege: A personal account of coming to see correspondence through work in women's studies (Working paper). Wellesley, MA: Wellesley College Center for Research on Women.

Murphy, J. W., \& Longino, C. F. Jr. (1997). Reason, the lifeworld, and appropriate intervention [guest editorial]. Journal of Applied Gerontology, 16, 149-151.

Stoller, E. P., \& Gibson, R. C. (1997). Worlds of difference: Inequality in the aging experience. Thousand Oaks, CA: Pine Forge Press.

Rose Campbell Gibson, Ph.D., is professor emeritus at the University of Michigan and immediate past editor-in-chief of The Gerontologist. She is the author of Blacks in an Aging Society and Worlds of Difference: Inequality in the Aging Experience (with Eleanor Palo Stoller).

Eleanor Palo Stoller, Ph.D., is Selah Chamberlain professor in the Department of Sociology at Case Western Reserve University. She is author of Worlds of Difference: Inequality in the Aging Experience (with Rose Campbell Gibson). 